\title{
STUDIEN ZUR DEUTSCHEN
}

LITERATUR

Band 168

Herausgegeben von Wilfried Barner, Georg Braungart, Richard Brinkmann und Conrad Wiedemann 

Thorsten Valk

\section{Melancholie \\ im Werk Goethes}

Genese - Symptomatik - Therapie

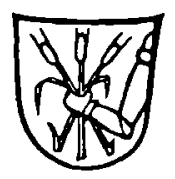

Max Niemeyer Verlag Tübingen 2002 
Die vorliegende Arbeit wurde gefördert durch ein Stipendium der Studienstiftung des deutschen Volkes.

Gedruckt mit Unterstützung der Deutschen Forschungsgemeinschaft.

D25

Bibliografische Information der Deutschen Bibliothek

Die Deutsche Bibliothek verzeichnet diese Publikation in der Deutschen Nationalbibliografie; detaillierte bibliografische Daten sind im Internet über bttp://dnb.ddb.de abrufbar.

ISBN 3-484-18168-0 ISSN 0081-7236

(C) Max Niemeyer Verlag GmbH, Tübingen 2002

Das Werk einschließlich aller seiner Teile ist urheberrechtlich geschützt. Jede Verwertung außerhalb der engen Grenzen des Urheberrechtsgesetzes ist ohne Zustimmung des Verlages unzulässig und strafbar. Das gilt insbesondere für Vervielfältigungen, Übersetzungen, Mikroverfilmungen und die Einspeicherung und Verarbeitung in elektronischen Systemen.

Printed in Germany. Gedruckt auf alterungsbeständigem Papier.

Satz und Druck: Gulde-Druck GmbH, Tübingen

Einband: Geiger, Ammerbuch 